\title{
TRADITIONAL PROCUREMENT VERSUS PUBLIC-PRIVATE PARTNERSHIP: A COMPARISON OF PROCUREMENT MODALITIES FOCUSING ON BUNDLING CONTRACT EFFECTS
}

Hojun Lee and Kiwan Kim

NO. 560

September 2018
ADB ECONOMICS WORKING PAPER SERIES 


\section{Traditional Procurement versus Public-Private Partnership: A Comparison of Procurement Modalities Focusing on Bundling Contract Effects}

Hojun Lee and Kiwan Kim

No. 560 | September 2018
Hojun Lee (hojunlee@kdi.re.kr; hlee16@worldbank.org) is Fellow at the Korea Development Institute (KDI) and Economist at the Development Economics Group, World Bank. Kiwan Kim (kwkim@kdi.re.kr) is Executive Director of the Public and Private Infrastructure Investment Management Center, KDI.

This paper has been prepared as background material for the Asian Development Outlook (ADO) 2017 Update theme chapter on Sustaining Development through Public-Private Partnership. The paper is also an extension of Lee (2017), a chapter of the KDI research monograph written in Korean. The authors would like to acknowledge the research assistance of Bomyi Yang and Chongwook Chung, and the helpful comments and editorial support provided by the ADB team. The views expressed in this paper are those of the authors and do not represent the position of the World Bank, its member countries, its Executive Directors, or KDI. 
(C) 2018 Asian Development Bank

6 ADB Avenue, Mandaluyong City, 1550 Metro Manila, Philippines

Tel +632632 4444; Fax +6326362444

www.adb.org

Some rights reserved. Published in 2018.

ISSN 2313-6537 (print), 2313-6545 (electronic)

Publication Stock No. WPS189560-2

DOI: http://dx.doi.org/10.22617/WPS189560-2

The views expressed in this publication are those of the authors and do not necessarily reflect the views and policies of the Asian Development Bank (ADB) or its Board of Governors or the governments they represent.

ADB does not guarantee the accuracy of the data included in this publication and accepts no responsibility for any consequence of their use. The mention of specific companies or products of manufacturers does not imply that they are endorsed or recommended by ADB in preference to others of a similar nature that are not mentioned.

By making any designation of or reference to a particular territory or geographic area, or by using the term "country" in this document, $A D B$ does not intend to make any judgments as to the legal or other status of any territory or area.

This work is available under the Creative Commons Attribution 3.0 IGO license (CC BY 3.0 IGO)

https://creativecommons.org/licenses/by/3.o/igo/. By using the content of this publication, you agree to be bound by the terms of this license. For attribution, translations, adaptations, and permissions, please read the provisions and terms of use at https://www.adb.org/terms-use\#openaccess.

This CC license does not apply to non-ADB copyright materials in this publication. If the material is attributed to another source, please contact the copyright owner or publisher of that source for permission to reproduce it. $\mathrm{ADB}$ cannot be held liable for any claims that arise as a result of your use of the material.

Please contact pubsmarketing@adb.org if you have questions or comments with respect to content, or if you wish to obtain copyright permission for your intended use that does not fall within these terms, or for permission to use the ADB logo.

Notes:

In this publication, “\$” refers to United States dollars.

ADB recognizes "Korea" as the Republic of Korea.

Corrigenda to ADB publications may be found at http://www.adb.org/publications/corrigenda. 


\section{CONTENTS}

TABLES AND FIGURES

ABSTRACT $v$ V

$\begin{array}{ll}\text { I. INTRODUCTION } & 1\end{array}$

II. THEORETICAL MODEL OF PROCUREMENT CONTRACTS 1

A. Basic Structure of a Public-Private Partnership in the Republic of Korea

B. Benchmark Model and the First Best Result 3

C. Traditional Procurement 4

D. Public-Private Partnerships 5

III. EMPIRICAL ANALYSIS OF PUBLIC-PRIVATE PARTNERSHIP PROJECTS IN THE REPUBLIC OF KOREA

A. Contract Characteristics $\quad 7$

B. Descriptive Statistics on the Changing Role of Investors 8

C. Modified Theoretical Models Considering the Characteristics of Public-Private Partnerships in the Republic of Korea

D. Empirical Examination of Investor Composition on Project Performance 11

$\begin{array}{lll}\text { IV. } & \text { CONCLUSION }\end{array}$

$\begin{array}{ll}\text { REFERENCES } & 15\end{array}$ 


\section{TABLES AND FIGURES}

\section{TABLES}

1 Composition of Investors by Public-Private Partnership Project Implementation Stage in the Republic of Korea

2 Results of Regression Models

\section{FIGURES}

$1 \quad$ Basic Structure of Public-Private Partnership in the Republic of Korea

2 Structure of a Public-Private Partnership Project in the Republic of Korea 


\begin{abstract}
This paper studies the optimal structure of procurement contracts between public and private sectors by mainly comparing two typical procurement types: traditional procurement and public-private partnership (PPP). We first set up a principal-agent model focusing on bundling effects of procurement based on Hart (2003), and lossa and Martimort (2015) to see under which conditions PPP has advantages over traditional procurement and vice versa. Then, we consider if the Republic of Korea's PPP structure in practice is well designed to maximize efficiency regarding the theoretical model. By reviewing the data on major investors and equity transactions of the Republic of Korea's PPP projects, we show that the bundling effects of PPP contracts, which is one of the main sources of efficiency, is limited under the current economic and political environment and derive policy implications for developing countries implementing PPP projects in the region.
\end{abstract}

Keywords: bundling contract, infrastructure, public-private partnership, traditional procurement JEL codes: H54, H81 


\section{INTRODUCTION}

The Republic of Korea is well known for its substantial success in using public-private partnership (PPP) as a mode of infrastructure financing in a short period of time. The PPP system was hastily promoted when the national treasury nearly went bankrupt after the Asian financial crisis. At that time, the government was unable to devote the resources needed to make the most of the new system; the emphasis in those crisis times was on pushing through as many PPP projects as possible, despite many constraints to doing this. Since then, the government has made a big effort to promote PPPs to relieve the financial burden on social infrastructure funding and tap the private sector's creativeness and efficiency.

Now is a good time to examine whether PPPs in the Republic of Korea have developed as they were originally intended, and whether they are moving in the right direction without causing negative side effects. Indeed, a similar exercise would be useful for other countries in Asia. Like the Republic of Korea, many adopted the PPP modality in the early 1990s and its use has been increasing. As Engel, Fischer, and Galetovic (2013, p. 84) put it, "As the economics of PPPs is still imperfectly understood, practice has run ahead of theory." Indeed, there is no theoretical basis or empirical evidence showing that PPPs can reduce the government's financial burden and make public investments more efficientas many private contractors and government administrators involved in PPP projects assert. Studies on projects show that PPPs may or may not lead to easing a government's financial burden and boosting efficiency either, depending on the project itself.

This paper begins with a theoretical analysis on PPPs as a principal financing method for public investment projects. We then review the theoretical models of PPPs' typical structures based on Hart (2003), and lossa and Martimort (2015), and examine from a social welfare perspective what aspects of PPPs increase efficiency. After that, we introduce PPP models that have been revised to reflect the Republic of Korea's actual situation, and compare them with the ideal PPP system. This analysis will show the gap between the country's actual situation and the ideal PPP model, which limits PPPs from boosting effectiveness and allows us to show ways to suggest improvements to the current system. We then examine whether the results from our theoretical models, constructed from observations of PPP contracts in the Republic of Korea, can be validated by actual data. This empirical analysis is done using the cases of 33 road projects, which are collected and managed by the Korea Development Institute's Public and Private Infrastructure Investment Management Center, and has detailed information on all PPP projects in the Republic of Korea. This paper closes with a discussion on the ways the Republic of Korea can overcome the limits of its own PPP system, as well as policy implications for developing countries that are implementing PPP projects in the region.

\section{THEORETICAL MODEL OF PROCUREMENT CONTRACTS}

\section{A. Basic Structure of Public-Private Partnership in the Republic of Korea}

A special purpose vehicle (SPV), a legal entity that acts as the concessionaire, needs to be established to implement a PPP project in the Republic of Korea. SPVs generally consist of construction companies, financial investors, and professional operators who recover their investment from construction profit, dividends, or interest payments. After being set up, an SPV then needs 
authorization from the competent authority, which is a procurement agency, to initiate a design-buildfinance-operate process.

In a traditional procurement, the competent authority selects a private firm to design and build a project. After financing the project, the government can either manage and operate a facility itself or select an operator to do this. In a PPP project, the whole implementation process is granted to a single entity. Figure 1 shows a typical PPP structure. The competent authority may be a public sector entity such as a local government or line ministry that is responsible for implementing a PPP project. It should consider, among other things, the feasibility of proposed projects and their consistency with related long-term policy directions.

Figure 1: Basic Structure of Public-Private Partnership in the Republic of Korea

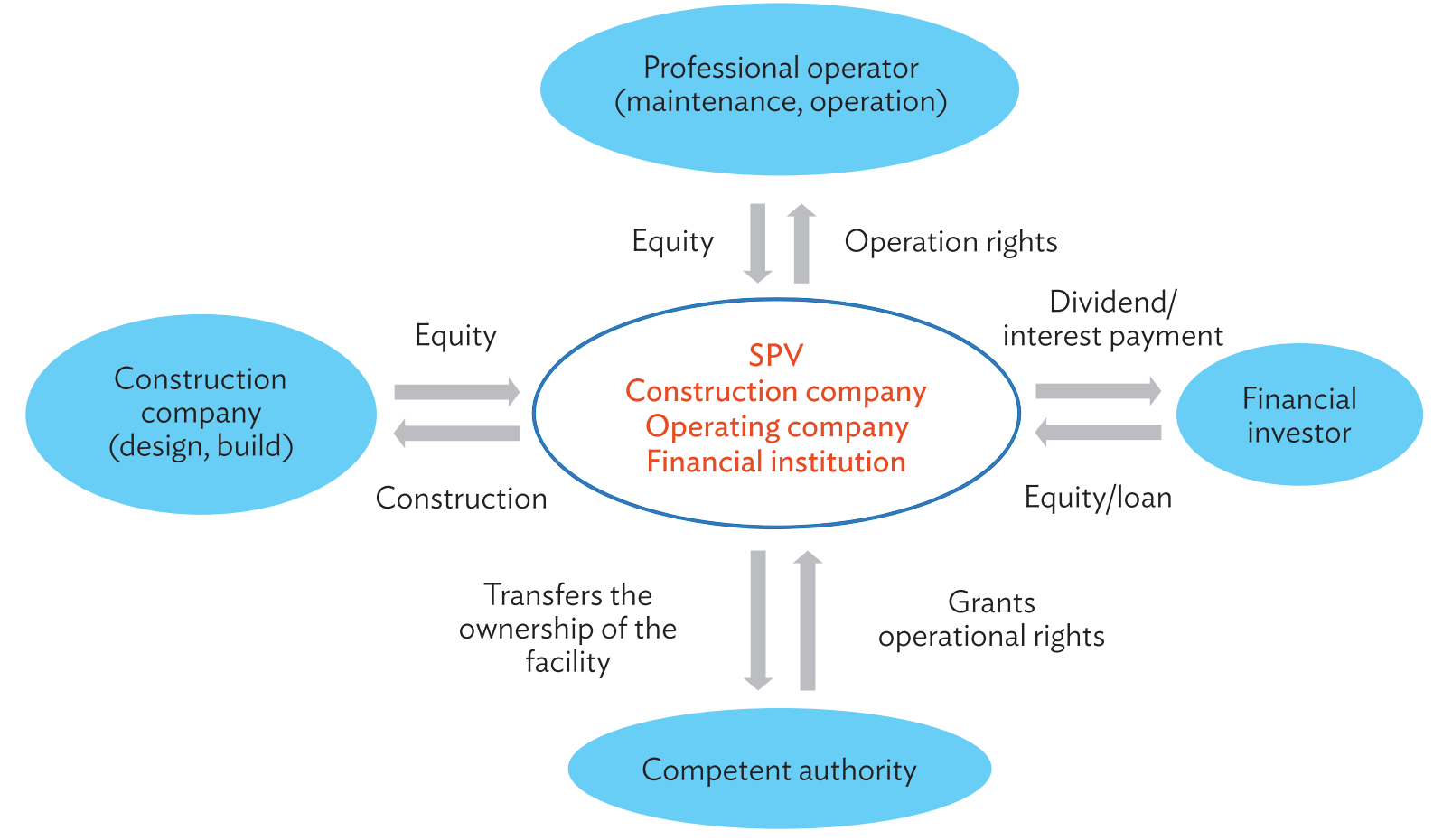

SPV = special purpose vehicle.

Source: Korea Development Institute, Public and Private Infrastructure Investment Management Center.

Among eligible PPP procurement methods, build-transfer-operate (BTO) and build-transferlease (BTL) methods are the most frequently chosen in the Republic of Korea. When the construction phase of a PPP project is completed, its ownership is transferred to the government in both BTO and BTL methods. The big difference between these two methods is the way SPVs recover their investment. In BTO projects, SPVs directly collect user fees as in the case of typical example of toll roads, while in BTL projects, concessionaires are given the right to operate a facility, and they receive government payments for a fixed period. The BTL method is used more frequently for PPPs for school and other education facilities, where the concessionaire receives a lease payment and operation costs from the government to recover its investment and make profit. 
As the Korean case shows, the PPP system is, in general, characterized by its procurement procedures in which designing, building, financing, and operating tasks are bundled, where SPVs decide how to maximize shareholders' benefit. In contrast, in traditional procurement, private contractors deal with such tasks under the concession of a government procurement agency.

\section{B. Benchmark Model and the First Best Result}

This section examines the characteristics of a PPP project with theoretical models, reflecting the basic PPP structure just discussed. We consider a principal-agent model in which a principal and an agent are risk-neutral to enable us to investigate the source of efficiency of PPP projects.

Consider a government $(G)$ that implements an infrastructure project, which consists of the following procedures: design, build, and operate. We suppose a private construction company (C) oversees the design and construction of a facility, and a private operating company (O) oversees the operation. We assume the discount rate is 0 in the model. The economic benefit of the infrastructure project, , is affected by C's effort during the construction period, $e$, which is private information of $\mathrm{C}$. $B$ is observable by both $\mathrm{G}$ and $\mathrm{C}$, after it is realized at the end of the operation period, but it is noncontractible. Thus, we assume that $\mathrm{G}$ can only prove whether $B$ is greater than criterion $B_{0}$, not the exact amount of $B$. The nonverification assumption is to reflect common practice in the real world, where the exact amount of a project's benefit cannot be measured; only the quality of the infrastructure is assessed by various objective criteria. ${ }^{1}$ Thus, the amount of $B$ is determined as follows. The effort, $e$, incurs the disutility, $d_{1}(e)$ to $C$.

$$
B=B_{0}+e+\varepsilon, \varepsilon \sim N\left(0, \sigma^{2}\right)
$$

The construction cost $(C C)$ is affected by $a$, the effort of $C$ to decrease the cost with the quality retained. $C C$ is also affected by the level of effort, $e$, to increase the quality of the infrastructure, and the disutility, $d_{2}(a)$, is incurred by $C$. As $C$ tries to increase the quality by increasing $e$, the construction cost should also increase. So, the cost function $I(e)$ is added to this cost. The following shows how $C C$ is affected by $a$ and $e$, as well as the basic construction cost $C C_{0}$ that is fixed and common knowledge:

$$
C C=C C_{0}-a+I(e)
$$

The operating cost $(O C)$ is affected by the level of efforts, $a$ and $e$, determined by $C$ during the construction. We suppose that as the cost-saving effort, $a$, during construction increases, higher operating cost is required. In other words, we assume that, given the level of quality, more is spent to retain the quality as $C$ chose the cheaper construction method. Further, because the quality is enhanced by the effort, $e$, during construction, the operating cost may increase or decrease. Higher quality sometimes requires higher costs to retain quality, or it sometimes saves costs with better technology.

Equation (3) shows how the operating cost is determined when $O C_{0}$ is the basic operating cost that is fixed and common knowledge. In the equation, positive $\lambda$ means the operating cost increases as the quality-enhancing effort, $e$, increases, and negative $\lambda$ means the operating cost decreases as $e$ increases.

1 For example, the benefit of a road project cannot be exactly measured. We can only measure traffic volume, average travel times, and similar measures that can provide indirect information on the quality of the road. 
4 | ADB Economics Working Paper Series No. 560

$$
O C=O C_{0}+C_{1}(a)+\lambda C_{2}(e)
$$

Here are the assumptions on the convexity of the cost or disutility functions:

Assumption 1

$$
\begin{aligned}
& d_{1}^{\prime}(a)>0, \quad d_{1}^{\prime \prime}(a)>0, \quad \lim _{a \rightarrow 0} d_{1}^{\prime}(a)=0, \quad \lim _{a \rightarrow \infty} d_{1}^{\prime}(a)=\infty \\
& d_{2}^{\prime}(e)>0, \quad d_{2}^{\prime \prime}(e)>0, \quad \lim _{e \rightarrow 0} d_{2}^{\prime}(e)=0, \quad \lim _{e \rightarrow \infty} d_{2}^{\prime}(e)=\infty \\
& I^{\prime}(e)>0, \quad I^{\prime \prime}(e)>0, \quad \lim _{e \rightarrow 0} I^{\prime}(e)=0, \quad \lim _{e \rightarrow \infty} I^{\prime \prime}(e)=\infty \\
& C_{1}^{\prime}(a)>0, \quad C_{1}^{\prime \prime}(a)>0, \quad \lim _{a \rightarrow 0} C_{1}^{\prime}(a)=0, \quad \lim _{a \rightarrow \infty} C_{1}^{\prime}(a)=\infty \\
& \lambda C_{2}^{\prime}(e)>0, \lambda C_{2}^{\prime \prime}(e)>0, \lim _{e \rightarrow 0} \lambda C_{2}^{\prime}(e)=0, \lim _{e \rightarrow \infty} \lambda C_{2}^{\prime}(e)=\infty
\end{aligned}
$$

For these settings, we now consider the first best result from the following maximization problem:

$$
\begin{gathered}
\max _{a, e} E\left[B-C C-O C-d_{1}(a)-d_{2}(e)\right] \\
\equiv \max _{a, e} B_{0}+e-C C_{0}+a-I(e)-O C_{0}-C_{1}(a)-\lambda C_{2}(e)-d_{1}(a)-d_{2}(e)
\end{gathered}
$$

Just like a central planner's problem, the objective function includes the social benefit of the infrastructure, $B$, and the social costs, $C C, O C, d_{1}(a)$, and $d_{2}(e)$. By Assumption 1 , the objective function of the problem is concave, so we can find the optimal solution by deriving the first-order conditions. The first best result is:

$$
\begin{gathered}
a: \quad C_{1}^{\prime}\left(a^{*}\right)+d_{1}^{\prime}\left(a^{*}\right)=1 \\
e: \quad I^{\prime}\left(e^{*}\right)+\lambda C_{2}^{\prime}\left(e^{*}\right)+d_{2}^{\prime}\left(e^{*}\right)=1
\end{gathered}
$$

Equations (5) and (6) show the first-order conditions for $a$ and $e$. Equation (5) implies that the marginal costs of decreasing $C C$ should be the same as the marginal benefit of decreasing $C C$. When $C$ increases the effort, $a$, both disutility of $C$ and the operating cost increase. Thus, the marginal social cost that includes the marginal $O C$ and the marginal disutility of $C$ (the left side of the equation) should be the same as the marginal benefit, which is 1, in social optimum. Equation (6) implies that the marginal cost of increasing the social benefit, $B$, should be the same as its marginal benefit. As the quality-enhancing effort, $e$, increases, the social costs, including $C C, O C$, and the disutility of $O$, increase. In social optimum, the marginal social cost of enhancing the quality should be the same as its marginal benefit. In reality, we cannot achieve the first best result because of the conflict of interests among $G, C$, and $O$. We now consider traditional procurement and PPP contracts. 


\section{Traditional Procurement}

Here, we study a typical traditional procurement mechanism and derive the equilibrium to compare it with the equilibrium under PPP. Let $T$ be the amount of transfer from $G$ to $C$, if $B$ is greater than or equal to $B_{0}$. Then, the following equation (7) is the maximization problem of $C$ to determine the amount of $a$ and $e$ :

$$
\max _{a, e} T-C C_{0}+a-I(e)-d_{1}(a)-d_{2}(e)
$$

By Assumption 1, the objective function of equation (7) is concave, so that we can derive the optimal level of efforts of $\mathrm{C}$ by the first-order conditions under traditional procurement. The conditions are:

$$
\begin{array}{ll}
\text { a: } & d_{1}^{\prime}\left(a_{t p}\right)=1 \\
\text { e: } & I^{\prime}\left(e_{t p}\right)+d_{2}^{\prime}\left(e_{t p}\right)=0
\end{array}
$$

Equation (8) shows how agent $C$ decides the level of effort to decrease $C C$. As $a$ increases by one unit, $C$ can save $C C$ by one unit. Thus, C's marginal benefit of increasing $a$ is one, which is the right side of the equation. The left side, $d_{1}^{\prime}\left(a_{t p}\right)$, implies C's marginal cost of increasing $a$ under traditional procurement. As a increases, $O C$ increases by $C_{1}^{\prime}(a)$, but $C$ does not care about the changes in $O C-$ that is the burden of operator $O$, which makes equation (8) different from equation (5). For maximizing social welfare, we should care about the marginal cost of $C_{1}$, while $C$ does not care in a traditional procurement contract, where $O C$ is not covered by $C$. Therefore, the optimal level of $a$ of $C$ under traditional procurement, $a_{t p}$, is greater than the first best level, $a^{*}$.

Proposition 1. The effort to decrease construction cost under traditional procurement $\left(a_{t p}\right)$ is greater than the first best level of the effort, i.e. $a_{t p}>a^{*}$.

Equation (9) shows how agent $C$ decides the level of effort to increase the benefit of the infrastructure. By increasing $e$ by one unit, the benefit of the infrastructure increases by one unit. However, $C$ only gets the fixed amount of compensation, $T$, regardless of the amount of $B$, if it is greater than $B_{0}$. Because $C$ covers the cost of $e, I(e)+d_{2}(e)$, while the agent does not get any benefit from it, $C$ will choose zero effort, thus, $e_{t p}=0$, which is obviously less than the socially optimal level, $e^{*}$.

Proposition 2. The effort to increase the benefit of the infrastructure under traditional procurement $\left(e_{t p}\right)$ is zero, which is less than the first best level of the effort, that is, $e_{t p}=0<e^{*}$.

As shown in Proposition 2, C chooses less effort level under traditional procurement. Because $\mathrm{C}$ only cares about profit, which excludes operating costs and the benefit of infrastructure, $\mathrm{C}$ chooses different effort levels, $a_{t p}$ and $e_{t p}$ from socially optimal levels, $a^{*}$ and $e^{*}$, which means there is some inefficiency under traditional procurement. In sum, the effort to decrease construction costs is overachieved, while the effort to increase infrastructure quality is underachieved.

\section{Public-Private Partnerships}

PPP contracts are considered in our model. In PPP, a government (G) makes a contract with a private party $(P)$ who builds and operates the infrastructure. In a typical BTO project, $P$ gets revenue from the user fee, with the revenue amount depending on the number of users, $N$, of the facility under a certain 
level of user fee. Let us assume that the user fee is fixed at $f$. Then, the amount of P's revenue is a linear function of $N$. We also suppose that $N$ is affected by $e$, P's effort to increase the benefit of the infrastructure is $N^{\prime}(e)>0, N^{\prime \prime}(e)<0$. This assumption implies the concavity of the function $N$ for $e$.

Because $\mathrm{P}$ oversees both construction and operation, $\mathrm{P}$ chooses $a$ and $e$ considering $\mathrm{P}$ 's revenue, the construction and operating costs, and disutility from the effort. We can then write P's maximization problem as follows:

$$
\max _{a, e} T(N(e))-C C_{0}+a-I(e)-O C_{0}-C_{1}(a)-\lambda C_{2}(e)-d_{1}(a)-d_{2}(e)
$$

By assumptions, the objective function of equation (10) is concave, so that we can find the optimal effort levels by the first-order conditions under PPP:

$$
\begin{gathered}
C_{1}^{\prime}\left(a_{p}\right)+d_{1}^{\prime}\left(a_{p}\right)=1 \\
I^{\prime}\left(e_{p}\right)+\lambda C_{2}^{\prime}\left(e_{p}\right)+d_{2}^{\prime}\left(e_{p}\right)=\frac{d T}{d N} \frac{\partial N}{\partial e}=f \cdot \frac{\partial N}{\partial e}
\end{gathered}
$$

Let us compare the conditions with the first best and traditional procurement results. We find that equation (11) is the same as equation (5), which means that the level of effort to decrease the construction cost is the same as the first best level. Therefore, we can achieve the first best level of $a$ under a PPP contract, while it is overachieved under a traditional procurement. Because the private party cares about both the construction and operating cost, $\mathrm{P}^{\prime} \mathrm{s}$ operating cost increases by $C_{1}^{\prime}(a)$ as $\mathrm{P}$ decreases the construction cost by one unit under PPP, while the construction company does not care about the operating cost increase under traditional procurement. That is why the optimal effort under a PPP project is less than for a traditional procurement.

Proposition 3. The effort to decrease the construction cost under PPPs $\left(a_{p}\right)$ is the same as the first best level of the effort, that is, $a_{p}=a^{*}$.

The left side of equation (12) is the same as that of the first best condition in equation (6). Thus, if the right side $f \cdot \frac{\partial N}{\partial e}$ is equal to 1 , the first best effort level can be achieved. If $f \cdot \frac{\partial N}{\partial e}>1$, the optimal effort level under PPP, $e_{p}$, is less than $e^{*}$, and if $f \cdot \frac{\partial N}{\partial e}<1, e_{p}$ is greater than $e^{*}$. In any case, $e_{p}$ is always positive, which means it is greater than 0 , the effort level under a traditional procurement. Therefore, we can say that the quality-enhancing effort under a PPP project is greater than for a traditional procurement.

Proposition 4. The effort to increase infrastructure quality under PPP $\left(e_{p}\right)$ contract is greater than under traditional procurement; that is, $e_{p}>e_{t p}$.

As we have seen, PPPs lead to more efficient results than traditional procurements mainly because private partners choose their effort levels. They consider both construction and operating costs under a PPP contract, while the construction company considers only construction costs, not operating costs. So, in our model, the main source of efficiency comes from the bundling effects of PPP contracts. We now examine the PPP projects in the Republic of Korea to see whether there are bundling effects that can improve the efficiency of procurement contracts. 


\section{EMPIRICAL ANALYSIS OF PUBLIC-PRIVATE PARTNERSHIP PROJECTS IN THE REPUBLIC OF KOREA}

\section{A. Contract Characteristics}

In principle, the structure of PPP procurement in the Republic of Korea is similar to the general PPP schemes discussed earlier. As shown in Figure 2, an SPV built an infrastructure facility by using private capital and transfers it to the competent authority. In return, it gets the operation and maintenance right for a predetermined period.

Figure 2: Structure of a Public-Private Partnership Project in the Republic of Korea

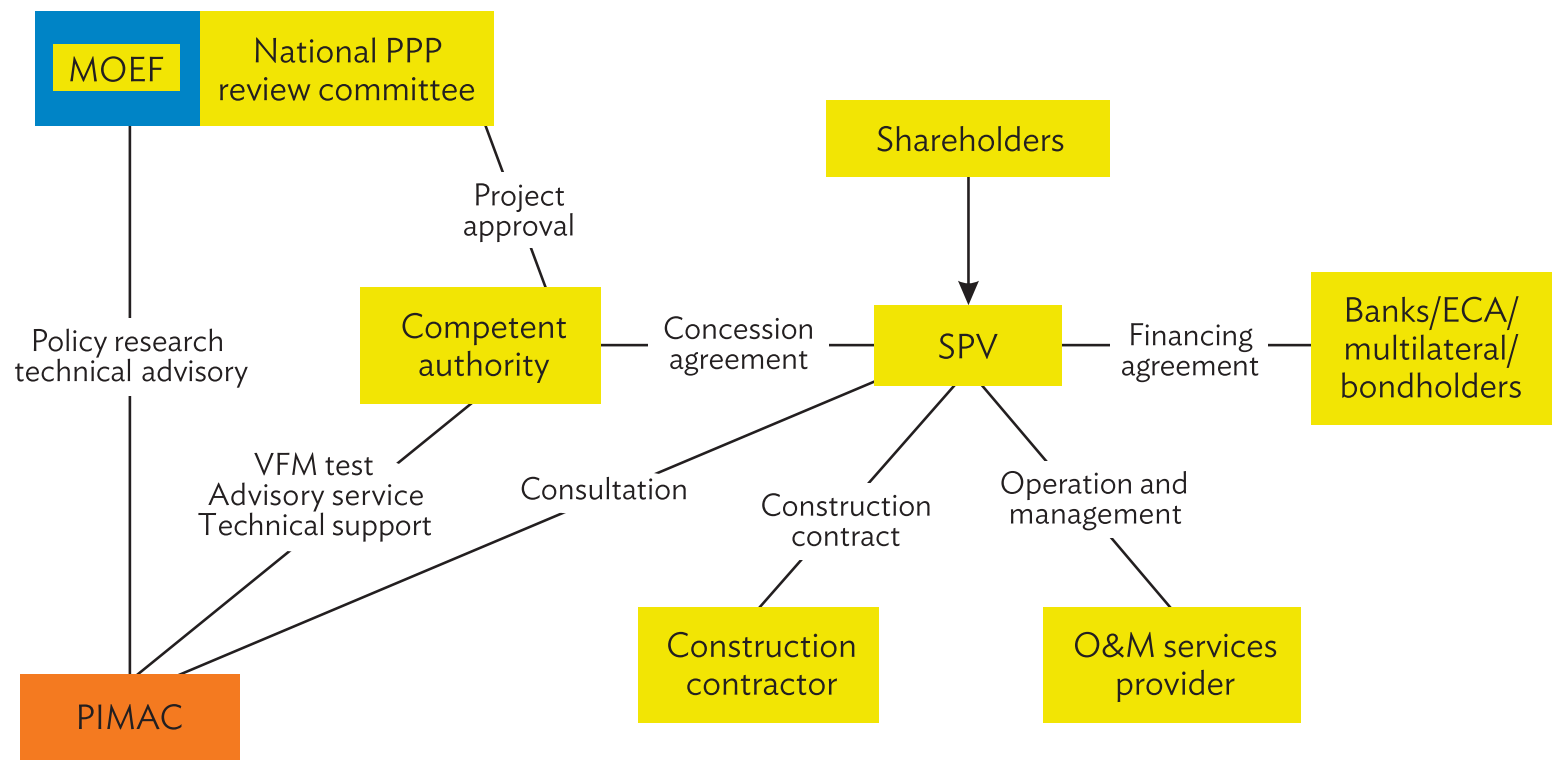

$\mathrm{ECA}=$ export credit agency, $\mathrm{MOEF}=$ Ministry of Economy and Finance, $\mathrm{O} \& \mathrm{M}=$ operation and maintenance, $\mathrm{PPP}=$ public - private partnership, PIMAC = Public and Private Infrastructure Investment Management Center, SPV = special purpose vehicle, VFM = value for money.

Source: Korea Development Institute, Public and Private Infrastructure Investment Management Center.

The SPV makes a legal agreement with the competent authority, which set the terms of PPP contracts; the SPV tends to have specific relations with diverse partners, or it sources out certain activities to external entities, such as construction companies, operation and maintenance companies, and financial investors. An SPV for a PPP project may often have various partners.

In the Republic of Korea, major PPP projects come under the supervision of the Ministry of Economy and Finance, and the Public-Private Partnership Review Committee. This is chaired by the strategy and finance minister, and is made up of government officials and private sector experts. The Public and Private Infrastructure Investment Management Center of the Korea Development Institute supports the PPP-related activities of the ministry and the committee. The center, among other things, provides technical assistance to competent authorities so that PPPs can be planned and implemented in alignment with the public interest. 


\section{B. Descriptive Statistics on the Changing Role of Investors}

This implementation structure of a PPP in the Republic of Korea does not substantially differ in some respects from the theoretical models, especially in terms of the composition and type of investors. Two major types of investors, construction investors and financial investors, may have different interests and expectations on PPP projects, which tend to determine their strategic behaviors and result in frequent changes in investor composition. Table 1 shows how PPP projects in the Republic of Korea have changed in terms of investor composition after the initial PPP contract; Table 1 is divided by implementation stages.

The first section of Table 1 shows the composition of the total amount of equity for BTO-type PPP projects in the Republic of Korea signed in June 2016, and decomposed by investor type. The total amount of equity is W12.5 trillion (around $\$ 11.6$ billion as of January 2018), of which construction investors contributed $58 \%$ at the initial agreement, but this decreases to $43 \%$ at the operation stage. Financial investors make up about 33\% at the initial signing, but the corresponding figure increases up to $42 \%$ at the operation stage.

The second section of Table 1 shows the same statistics as the first section, yet only for the sample without the nine delayed PPP projects that failed to raise capital due to the global recession in 2008 because we do not consider them in normal operation. Here, the share of construction investors decreased from $65 \%$ at the time of initial signing to $43 \%$ at the operating stage, while the financial investors increased their share from $24 \%$ to $42 \%$ between the same two project stages.

The third section of Table 1 shows the same result as the second section, yet this time calculated only for projects in operation. The result emphasizes the same trend more dramatically: construction investors have contributed up to $70 \%$ of total capital, but their share fell to $43 \%$ when projects go into operation, whereas financial investors have more than doubled their share from the initial 20\%-42\% at the operation stage. This tendency-construction investors tend to raise most capital at the time of initial signing, but the major function of raising capital is transferred to financial investors as projects go into operation-is one of the prevailing characteristics of the Republic of Korea's PPP market that distinguishes it from other major countries with viable PPP markets. ${ }^{2}$ Two factors may be relevant to the emergence of this trend in the Republic of Korea. The first is the more active role of construction investors in the takeoff phase of the country's PPP market. After the Asian financial crisis, the government promoted PPPs to complement the limited fiscal room for infrastructure investment. At that time, however, PPPs were little understood, and the country's financial markets were not ready for this type of investment. Back then, large construction companies with sufficient capital initiated PPPs to participate in large government construction contracts, rather than to gain returns from a particular project. In the countries with a developed PPP market, these projects are often designed and implemented by developers, but this has never been widely practiced in the Republic of Korea.

2 We also conducted an additional analysis (not shown here) that examines which type of investors was dominant for each project stage. Here, we observed that large construction investors took on the major role of capital raising during the construction phase after the initial signing through to design implementation, while financial investors contribute to major parts of capital at the operation stage. 
Table 1: Composition of Investors by Public-Private Partnership Project Implementation Stage in the Republic of Korea (W billion)

\begin{tabular}{|c|c|c|c|c|}
\hline Investor Type & Initial Signing & $\begin{array}{c}\text { Approval of } \\
\text { Implementation } \\
\text { Design }\end{array}$ & Construction & Operation \\
\hline \multicolumn{5}{|c|}{ A. PPP Projects with an Initial Signed Contract } \\
\hline \multirow{2}{*}{$\mathrm{Cl}$} & 7,241 & 6,236 & 6,226 & 4,011 \\
\hline & $57.70 \%$ & $55.70 \%$ & $51.40 \%$ & $43.30 \%$ \\
\hline \multirow{2}{*}{$\mathrm{FI}$} & 4,133 & 3,555 & 4,564 & 3,871 \\
\hline & $32.90 \%$ & $31.80 \%$ & $37.70 \%$ & $41.80 \%$ \\
\hline \multirow{2}{*}{ O\&M } & 950 & 1,061 & 1,060 & 1,169 \\
\hline & $7.60 \%$ & $9.50 \%$ & $8.80 \%$ & $12.60 \%$ \\
\hline \multirow{2}{*}{ Others } & 230 & 339 & 257 & 207 \\
\hline & $1.80 \%$ & $3.00 \%$ & $2.10 \%$ & $2.20 \%$ \\
\hline Total & 12,554 & 11,191 & 12,107 & 9,258 \\
\hline
\end{tabular}

B. Without the Distressed Projects due to Global Recession ${ }^{a}$

\begin{tabular}{lrrrr}
\hline Cl & 6,739 & 6,012 & 5,995 & 4,011 \\
& $64.94 \%$ & $61.47 \%$ & $57.16 \%$ & $43.33 \%$ \\
$\mathrm{FI}$ & 2,525 & 2,426 & 3,230 & 3,871 \\
& $24.33 \%$ & $24.81 \%$ & $30.80 \%$ & $41.81 \%$ \\
O\&M & 884 & 1,003 & 1,005 & 1,169 \\
& $8.52 \%$ & $10.25 \%$ & $9.58 \%$ & $12.63 \%$ \\
Others & 230 & 339 & 257 & 207 \\
Total & $2.22 \%$ & $3.47 \%$ & $2.45 \%$ & $2.23 \%$ \\
\hline C. PPP Projects in Operation, as of June 2016 & 9,779 & 10,487 & 9,258 \\
\hline \multirow{2}{*}{ Cl } & 10,377 & 5,843 & & \\
& 6,351 & $64.03 \%$ & $59.29 \%$ & $43.33 \%$ \\
FI & $68.98 \%$ & 1,984 & 2,786 & 3,871 \\
& 1,855 & $21.73 \%$ & $28.35 \%$ & $41.81 \%$ \\
O\&M & $20.14 \%$ & 963 & 961 & 1,169 \\
& 774 & $10.55 \%$ & $9.77 \%$ & $12.63 \%$ \\
Others & $8.41 \%$ & 336 & 255 & 207 \\
Total & 227 & $3.68 \%$ & $2.59 \%$ & $2.23 \%$ \\
\hline
\end{tabular}

$\mathrm{Cl}=$ construction investor, $\mathrm{FI}=$ financial investor, $\mathrm{O} \& \mathrm{M}=$ operation and maintenance, $\mathrm{PPP}=$ public - private partnership.

a Nine projects were excluded: Sangju-Yeongchon Highway, Pusan New Port Second Road, Anyang-Seongnam Highway, Bibong-Maesong Highway, Oksan-Ochang Highway, Incheon-Gimpo Highway, Gwangju-Wonju Highway, GuriPocheon Highway, and Suwon-Gwangmyung Highway.

Note: $\$ 1 \approx W_{1,076}$ (as of January 2018 ).

Source: Korea Development Institute, Public and Private Infrastructure Investment Management Center. 
The second reason is the conservative investment attitude of the country's financial institutions. Because PPP projects often come with considerable risk, financial investors getting into a PPP must conduct a project risk analysis, and hedge against perceived risks before making an investment decision. However, the Korean financial institutions have avoided investing in the early stage of PPP projects, preferring instead to come at the postconstruction stage, where project risks have been eliminated for the most part. Financial institutions also tend to request substantial collateral from SPVs for loan approvals, which has considerably hampered the participation of developers, who have far less capital room compared with large construction investors. On the other side, financial institutions have provided SPVs, in which they participated as equity holders, with subordinated loans with higher interest rates, which has made it possible for construction investors to enjoy decent returns, even though they began investing at later stages with substantially less risk.

\section{Modified Theoretical Models Considering the Characteristics of Public-Private Partnerships in the Republic of Korea}

Here, we modify the previous theoretical model to reflect the characteristics of PPP contracts in the Republic of Korea. Let $T$ be the amount that a financial investor pays the construction investor when it takes over the project after the completion of construction. Usually, financial investor takes over a project after a couple of years of operation, and $T$ is determined by the number of users during the initial operation years, as well as the bargaining powers of both parties. Suppose a construction investor knows the bargaining powers of each side and the function of $N(e)$ when the investor determines effort levels, $a$ and $e$. The following is the construction investor's maximization problem:

$$
\max _{a, e} T(N(e))-C C_{0}+a-I(e)-d_{1}(a)-d_{2}(e)
$$

Let us assume that $T$ is a linear function of the number of users $N$. Then, the optimal effort levels can be derived by the following first-order conditions:

$$
\begin{gathered}
d_{1}^{\prime}\left(a_{k}\right)=1 \\
I^{\prime}\left(e_{k}\right)+d_{2}^{\prime}\left(e_{k}\right)=\frac{d T}{d N} \frac{\partial N}{\partial e}
\end{gathered}
$$

Equation (14) is the same as equation (8), which is the first-order condition under a traditional procurement. This means that the level of effort to decrease construction costs under PPP in the Republic of Korea is the same as that for traditional procurement, and greater than the first best level. Even for PPP contracts, a construction investor will sell the project and not care about the operation cost, and so the construction investor chooses the effort level, $a_{k}$, without considering the operating cost.

Proposition 5. The effort to lower construction costs in PPP contracts in the Republic of Korea is greater than the first best level of the effort; that is, $a_{k}=a_{t p}>a^{*}$.

The left side of equation (15) is the same as equation (9), while the right side is different. This means that, as the right side comes closer to zero, the quality-enhancing effort level of PPP in the Republic of Korea comes closer to traditional procurement. If $N$ is not sensitive to the effort level or $T$ is not sensitive to $N$, then its effort level that satisfies equation (15) is close to zero. Therefore, under certain conditions, the effort level chosen by a construction investor is the same as for a traditional procurement. 
Proposition 6. If $N$ is not affected by $e$, or $T$ is not affected by $N$, then the effort level under PPP contract in the Republic of Korea is zero; that is, $e_{k}=e_{t p}=0$.

Propositions 5 and 6 say that PPP contracts do not guarantee efficiency improvement. And under some conditions, we do not achieve it. Therefore, introducing a PPP system is not enough to enhance procurement efficiency, and bundling contract effects should lead efficiency improvements under a PPP system.

\section{Empirical Examination of Investor Composition on Project Performance}

Here, we examine the theoretical model constructed from the observation in the real statistics on PPP projects in the Republic of Korea. For this, we constructed a small sample of 33 PPP projects using the Infralnfo database, which is constructed and managed by the Ministry of Economy and Finance and Public and Private Infrastructure Investment Management Center. To control the different properties of each project as far as possible, we chose only 33 road PPP projects that are currently in operation.

We focused on the possible impact that the initial composition and changes in the equity structure may have on the output indicators of each PPP project. To determine whether and to what extent the equity structure has changed, we gathered information from the Infralnfo database on the share of construction and financial investors at different project pipelines (for example, initial signing, construction, and operation). The focus of this analysis was to examine how the change of equity structure can induce cost-saving behavior by construction investors. For this, we compared the total private investment volume on the initial contract with the corresponding figures on the final audit report (these are from real audit reports of PPP projects). From the results of the comparison, we considered two dependent variables: the relative change of project cost compared to the cost estimation at the initial signing, and the absolute difference of audited private investment volume and initial private investment volume.

The main hypotheses that we are trying to verify are twofold. First, the higher the share of construction investors at the initial contract signing, the more prevalent will be the cost-saving efforts by the SPV, since construction investors tend to focus on maximizing short-term profits by reducing construction costs. Second, because construction investors leave the project after construction, which will be measured by the difference in the share of their equity structure before and after construction, they will show a great tendency for reducing construction costs.

As noted earlier, we have measured the composition of investors within each PPP project, and followed its changes during the project pipeline. The dependent variable for the models is the difference in private investment volume between the initial agreement and the final audit report. Key explanation variables are the share of construction investors in the initial equity structure, for the first part of the analysis in this paper, and the change in share of construction investors before and after the construction for the second part. 
Table 2: Results of Regression Models

\begin{tabular}{|c|c|c|c|c|}
\hline \multirow[b]{2}{*}{ Explanatory Variables } & Model 1 & Model 2 & Model 3 & Model 4 \\
\hline & \multicolumn{2}{|c|}{ (\% of investment volume) } & \multicolumn{2}{|c|}{ (difference in investment volume) } \\
\hline \multirow[t]{2}{*}{ Share of $\mathrm{Cls}$} & 2.730 & - & 22,949 & - \\
\hline & $(2.820)$ & & $(15,413)$ & \\
\hline \multirow[t]{2}{*}{ Change in share of $\mathrm{Cls}$} & - & -1.820 & - & $-32,624^{*}$ \\
\hline & & $(3.340)$ & & $(17,519)$ \\
\hline \multirow[t]{2}{*}{ Solicited } & 1.590 & 1.590 & 5,393 & $-1,442$ \\
\hline & $(2.810)$ & $(2.850)$ & $(15,901)$ & $(14,934)$ \\
\hline \multirow[t]{2}{*}{ MRG } & $-5.560^{*}$ & $-5.270^{*}$ & $-32,304^{* *}$ & $-35,065^{* *}$ \\
\hline & $(2.890)$ & $(2.890)$ & $(14,575)$ & $(14,144)$ \\
\hline \multirow[t]{2}{*}{ Competent authority dummy } & 3.220 & 3.560 & 14,050 & 26,808 \\
\hline & $(2.040)$ & $(2.410)$ & $(28,625)$ & $(23,745)$ \\
\hline \multirow[t]{2}{*}{ Initial investment volume } & - & & $0.048^{*}$ & $0.054^{* *}$ \\
\hline & & & $(0.024)$ & $(0.020)$ \\
\hline \multirow[t]{2}{*}{ Constant } & $5.880^{* *}$ & $6.480^{* * *}$ & $-8,200$ & $-12,534$ \\
\hline & $(2.170)$ & $(2.260)$ & $(33,579)$ & $(27,708)$ \\
\hline R-squared & 0.159 & 0.147 & 0.432 & 0.463 \\
\hline Number of observations & 33 & 33 & 33 & 33 \\
\hline
\end{tabular}

Table 2 shows the results of regression models. Contrary to our expectations, we could not observe any statistically significant impact of both the initial share of construction investors and the change in their share on reducing project cost when we used the relative change in project cost as a dependent variable in models 1 and 2 , but using the absolute difference of investment volume (models 3 and 4) as a dependent variable, the change in the share of construction investors has a negative and statistically significant effect on the dependent variable (model 4), while the initial share of construction investors has no significant effect on reducing the project cost (model 3). That means that the greater the decrease of a construction investor's share after the initial contract signing, the bigger is the cost reduction that can be expected by the time the project goes into operation.

Another interesting result is on the minimum revenue guarantee (MRG). In all four models, the projects with an MRG showed a statistically significant cost reduction, and this is more pronounced in models 3 and 4. Although further analysis is needed to examine this result, it nevertheless seems to result from the fact that PPP projects with MRGs are often initiated mainly by financial investors or institutions; since MRGs were favored by both construction and financial investors due to lucrative revenue prospects, hence, both investors tend to participate much longer in the projects, which consequently may contribute to the project's efficiency.

Empirical results show that our hypothesis on the relationship between investor composition and cost reductions of PPP projects can only be partially verified. When using investment volume in relative terms as a dependent variable, we could not find a statistically significant effect, while the 
model using investment volume in absolute terms showed a significant, yet weak, effect. This rather disappointing result may be because of the availability of only a very small number of PPP projects for the data construction. But a significant result can be expected once more PPP project cases become available in the future.

\section{CONCLUSION}

We can derive some policy implications from the analysis. The most important one is that PPPs are not always more efficient than traditional procurements. Only if the contracts and implementation of PPPs are well designed the efficiency of these partnerships can be enhanced. As seen in the PPP model for the Republic of Korea, the results are similar to those from a traditional procurement, rather than to an ideal PPP. This shows that contractors only focus on maximizing short-term profits by minimizing construction cost rather than maximizing overall profit from the whole cycle of the project. Should a government promote PPPs as an alternative to traditional procurement to enhance efficiency, it needs to make the PPP mechanism as close as possible to the ideal model of a PPP. From the Republic of Korea's perspective, the incentive structure of construction companies, who only care about minimizing cost but not maximizing the overall net benefit of a project, needs to be changed. Strengthening competition in PPP markets would be a good way of going about this.

In the Republic of Korea, where construction companies rather than financial institutions play major roles, the competition becomes ineffective when some of the largest construction companies consist a consortium and submits a PPP proposal. So, we can consider introducing a formal regulation that limits the number of large construction firms that consist of one consortium in a PPP project bidding, which has been tried in the request for proposals of some projects in the Republic of Korea.

Also, we need to promote financial investors to play leading roles in developing and implementing PPP projects. One way is that we utilize newly introduced BTO-adjusted and BTO-risk sharing scheme that can reduce the project risk, which was one of the main challenges making the investors passive in the market. Another way is that we encourage infrastructure funds to invest in more PPP projects for which the system and regulation should be supplemented to allow the funds to diversify their investment among various PPP projects.

In sum, the bundling effect is a key component that affects the efficiency of PPP projects. Thus, we have to examine if it is effective and, if not, like many cases of the Republic of Korea, the problems that reduce the effect should be resolved to maximize the efficiency of a PPP project. 


\section{REFERENCES}

Engel, Eduardo, Ronald Fischer, and Alexander Galetovic. 2013. "The Basic Public Finance of PublicPrivate Partnerships.” Journal of the European Economic Association 11 (1): 83-111.

Hart, Oliver. 2003. "Incomplete Contracts and Public Ownership: Remarks, and an Application to Public-Private Partnerships.” Economic Journal 113 (86): C69-C76.

lossa, Elisabetta, and David Martimort. 2015. "The Simple Microeconomics of Public-Private Partnerships.” Journal of Public Economic Theory 17 (1): 4-48.

Lee, Hojun. 2017. "PPP Policy Suggestions for Improving the Efficiency of the Public Investment." In Public Investment for Enhancing Productivity, edited by Jaejoon Lee, Kang-Soo Kim, Sungmin Han, Changwoo Nam, Hyungtai Kim, Sanghoon Ahn, Jongyearn Lee, Weh-Sol Moon, and Hojun Lee. KDI Research Monograph 2017-05. 


\section{Traditional Procurement versus Public-Private Partnership: A Comparison of Procurement Modalities Focusing on Bundling Contract Effects}

This study explores an optimal structure of procurement contracts between the public and private sectors by comparing traditional procurement and public-private partnerships (PPP). The study sets up a principal-agent model, focusing on bundling effects of procurement, and shows that this effect is one of the main sources of efficiency gains for PPPs. An examination of the PPP project data reveals that the efficiency gain has not been fully realized in the Republic of Korea due to the imbalanced contract participation of different types of investors.

\section{About the Asian Development Bank}

ADB is committed to achieving a prosperous, inclusive, resilient, and sustainable Asia and the Pacific, while sustaining its efforts to eradicate extreme poverty. Established in 1966, it is owned by 67 members48 from the region. Its main instruments for helping its developing member countries are policy dialogue, loans, equity investments, guarantees, grants, and technical assistance. 